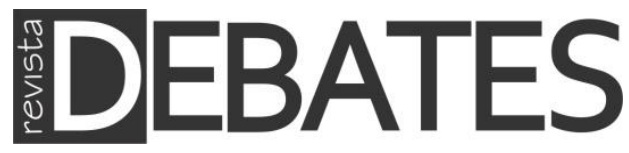

\title{
O Estado como unidade de análise dos sistemas regionais: impactos na estrutura sistêmica da América do Sul
}

\section{The State as a unit of analysis of regional systems: impacts in the systemic structure of South America}

\section{Ana Luiza Vedovato \\ Igor Castellano da Silva}

\section{Resumo}

O presente estudo avalia a relação entre unidades sistêmicas, a partir das características e aspectos formativos dos Estados, e estruturas sistêmicas profundas, na configuração do sistema regional sulamericano no período pós-independência (1810-2010). Nossa hipótese é que as evoluçóes e mudanças pelas quais passam os sistemas regionais parecem estar condicionadas, para além de causas interacionais e estruturais, pelas características e processos históricos dos Estados que os integram, podendo ser identificados em três mecanismos principais: 1) como tipos/unidades constituintes do sistema, a partir dos processos de formação e transformação dos Estados; 2) como agentes das interações sistêmicas; e 3) como elementos estruturadores, a partir de suas características, relações e dinâmicas internas. A adoção de perspectiva eclética e aliada à Sociologia Histórica possibilita avaliar a conexão dos processos históricos com mudanças estruturais observadas no sistema regional sul-americano.

\section{Palavras-chave}

América do Sul; Estado; Sistema Regional; Estrutura Sistêmica.

\begin{abstract}
This study evaluates the relationship between systemic units based on the characteristics and formative aspects of States and systemic deep structures in the configuration of the South American regional system in the post-independence period (1810-2010). Our hypothesis is that the evolutions and changes through which regional systems pass seem to be conditioned by the State's historical characteristics and processes, besides interactional and structural causes. These historical processes can be identified from three main mechanisms: 1) as constituent types/units of the system, from the processes of State formation and transformation; 2) as agents of systemic interactions; and 3) as structuring elements, based on their characteristics, relations and internal dynamics. The adoption of an eclectic perspective allied to the contributions of Historical Sociology makes it possible to evaluate the connection of historical processes with the structural changes in the South American regional system.
\end{abstract}

\section{Keywords}

South America; State; Regional System; Systemic Structure. 


\section{Introdução ${ }^{1}$}

Nas Relações Internacionais, o período do pós-Guerra Fria é marcado pelo protagonismo que as regiôes passaram a ter na política internacional e nos estudos das Relaçóes Internacionais, principalmente no contexto dos debates do Novo Regionalismo. Na América do Sul, tal tendência tornou-se mais evidente diante do aprofundamento da unipolaridade regional, com a consolidação do Brasil como potência regional e a articulação e fortalecimento de novas iniciativas de cooperação e integração. Esse contexto incentivou o desenvolvimento de diversos estudos sobre essas temáticas, tendo como foco principal questóes relacionadas à atuação do Brasil como potência e líder regional, e às dinâmicas interacionais dos atores regionais em torno da institucionalização de processos de integração.

No nível das unidades, contudo, grande parte dos estudos geralmente parte de análises de política externa (LIMA e HIRST, 2006; VARAS, 2008; BURGES, 2008 e 2015; SPEKTOR, 2010; VIGEVANI e RAMANZINI JÚNIOR, 2010; TEIXEIRA, 2011; LIMA, 2013; RODRIGUEZ, 2012; MALAMUD e RODRIGUEZ, 2013; SCHENONI, 2012a, 2012b e 2014), sem aprofundar observações sobre as características e aspectos formativos dos Estados e as relações Estado-sociedade. Aspectos estruturais também são menosprezados, mesmo entre aqueles que analisam aspectos da estrutura do sistema (ex. SCHENONI, 2012a, 2012b, 2014 e 2016; REZENDE, 2016), ignorando-se a possibilidade de mudança nas estruturas profundas do sistema regional, como a ordem sistêmica e o princípio ordenador (VEDOVATO, 2017; CASTELLANO e VEDOVATO, 2019). Assim, apesar de avanços na área, principalmente a partir de perspectivas como a do Novo Regionalismo, que possibilitaram a interpretação das regióes como sistemas próprios e autônomos, os estudos sobre a região caracterizam-se por limitada perspectiva histórica (VEDOVATO, 2017; CASTELLANO e VEDOVATO, 2019) e dificilmente incorporam às suas análises perspectivas endógenas sobre o Estado para pensar o papel das unidades sistêmicas nas dinâmicas regionais e interacionais (CASTELLANO, 2017; GRANATO e BATISTA, 2017). A falta de observação sobre a conexão entre aspectos das unidades sistêmicas, variáveis interacionais e

\footnotetext{
${ }^{1}$ A pesquisa foi realizada com apoio da Coordenação de Aperfeiçoamento de Pessoal de Nível Superior - Brasil (CAPES) - Código de financiamento 001. O trabalho é produto do projeto "Ordens sistêmicas: transformaçóes e impactos nas relaçóes internacionais”, no âmbito do Grupo de Estudos em Capacidade Estatal, Segurança e Defesa - GECAP/UFSM. Agradecemos, ainda, ao Prof. Dr. Leonardo Granato pelas orientações e comentários envolvendo uma primeira versão deste trabalho.
} 
estruturais, limita a compreensão de mudanças macro-históricas pelas quais o sistema regional se desenvolveu.

Diante desse desafio teórico e empírico, este estudo avalia a relação de coconstituição entre aspectos das unidades sistêmicas - como as características e aspectos formativos dos Estados e as relações Estado-sociedade - e aspectos da estrutura sistêmica profunda na configuração do sistema regional sul-americano no pós-independência. Nosso argumento, em conformidade com Hans Abrahamsson (2000) e Kalevi J. Holsti (2004), é que compreender as especificidades e características formativas dos Estados nas regiôes parece ser um caminho decisivo para que se avance nas análises dos sistemas regionais, produzindo maior entendimento sobre o impacto das unidades na estrutura sistêmica regional e contribuindo para os avanços e perspectivas teóricas oriundos do Novo Regionalismo. Diante desse desafio, a adoção de uma perspectiva aliada à Sociologia Histórica possibilita avaliar a conexão de processos históricos com as mudanças observadas no sistema regional. $\mathrm{O}$ trabalho busca inserir nesta agenda de pesquisa uma proposta de análise, trazendo como exemplo estudo empírico a respeito da estrutura sistêmica na América do Sul, de modo a contextualizar o argumento.

O trabalho divide-se em três seções. Na primeira seção, procura-se avaliar a agenda de pesquisa na qual este trabalho está inserido, discutindo as contribuições, desafios e lacunas do Novo Regionalismo a respeito do caso sul-americano e apresentando a perspectiva teórica e o modelo de análise utilizados. A segunda seção discute a categoria analítica do Estado na disciplina de Relações Internacionais e dos estudos regionais. Destacam-se as contribuiçôes derivadas da Sociologia Histórica e retomam-se contribuiçóes latino-americanas sobre o conceito de Estado e sua operacionalização para avaliar sua relação com a formação e transformaçóes no sistema regional. Por fim, a terceira seção apresenta uma discussão inicial sobre as possíveis formas de impacto dos elementos das unidades, a partir do Estado e suas características internas, nas estruturas sistêmicas regionais, valendo-se do caso do sistema regional sul-americano no pós-independência. Propomos a hipótese, a ser testada em estudos futuros, de que há três mecanismos pelos quais os Estados impactam os processos de estruturação regional, sendo eles 1) como tipos/unidades constituintes do sistema, a partir dos processos de formação e transformaçáo dos Estados; 2) como agentes das interaçôes sistêmicas; e 3) como elementos estruturadores, a partir de suas características, relações e dinâmicas internas. 


\section{O Novo Regionalismo e o estudo de regiões: avanços, limites e o modelo analitico de sistemas regionais}

Os estudos sobre regiôes ganharam maior destaque na literatura de Relações Internacionais no pós-Guerra Fria, tanto em seu aspecto empírico quanto pela sua dimensão teórica. Em primeiro lugar, esse período é caracterizado pela tendência que levou as regiôes a se tornarem o espaço de maior relevância, e por vezes prioritário, das interações estatais, tanto como lócus de rivalidade quanto de aproximação mútua e cooperação entre atores regionais. A América do Sul foi uma das regióes de destaque, principalmente a partir da década de 1990, por meio da inauguração e do aprofundamento das iniciativas de cooperação e integração regional, que passavam a se constituir na região como resposta às novas dinâmicas da globalização e da regionalização, contrastando com as opçôes hemisféricas que ensaiavam se articular no mesmo período, como a ALCA (SOUZA, 2012).

Foi num segundo momento, no entanto, que os estudos sobre regióes ganharam espaço e passaram a ser organizados na disciplina sob o guarda-chuva da agenda de pesquisa focada nas regiōes (HURRELL, 1995; FAWCETT, 2004; KELLY, 2007; FAWN, 2009). A organização de uma agenda dedicada aos estudos de regiôes permitiu que a disciplina se voltasse, também, para análises de regióes e atores regionais até então marginalizados na produção científica e teórica das Relações Internacionais, passando a contemplar particularidades dos sistemas regionais do Terceiro Mundo² (KELLY, 2007; CASTELLANO, 2017), inclusive a América do Sul. Essa tendência pode ser enquadrada no campo do chamado Novo Regionalismo, que passou a compreender as regióes, mais amplamente, como configuradas a partir de aspectos sociais e políticos (HEMMER e KATZENSTEIN, 2002) e definidas pelo grau de interação entre as unidades (HURRELL, 1995), configurando sistemas próprios e relativamente autônomos.

Apesar dos importantes avanços teóricos para o estudo da região, grande parte dos trabalhos na área reproduzem análises focadas em aspectos interacionais dos

\footnotetext{
${ }^{2}$ A utilização do termo "Terceiro Mundo", neste trabalho, tem correspondência aos Estados e regióes pertencentes ao também chamado Sul Global. Distanciando-se da percepção de seu significado no contexto da Guerra Fria, opta-se pela denominação de "Terceiro Mundo" pelos aspectos históricos e políticos comuns que conectam os Estados da categoria à sua definição. A proposta deriva de trabalhos como os de Christopher Clapham (1985) e Mohammed Ayoob (1995), ao abordarem particularidades dos processos de construção do Estado e da nação no Terceiro Mundo, assim como das relaçóes entre Estado e sociedade.
} 
atores regionais (CASTELLANO e VEDOVATO, 2019). A despeito do característico "estadocentrismo" da disciplina, ao tratar como atores regionais principais os Estados que constituem o sistema regional em questão, discussôes sobre os processos de formação e as características desses Estados são recorrentemente ignoradas. Exceçôes importantes podem ser encontradas em estudos como os de Fred Halliday (1987), Peter Vale (1990, 2001 e 2003), Mohammed Ayoob (1995 e 1999), Hans Abrahamsson (2000) e Kalev Holsti (2004). Entretanto, tais exemplos são escassos frente aos estudos que reproduzem o mesmo limite identificado por Wendt (1987) no individualismo sistêmico waltziano, qual seja, o de não oferecer uma teoria clara sobre a sua unidade de análise principal. Frente a esse desafio, uma análise mais aprofundada sobre nível das unidades torna-se elementar para a compreensão do sistema regional em seu todo.

Todavia, qualquer perspectiva sobre processos de formação e transformação de unidades sistêmicas carece de uma visão macro-histórica sobre processos políticos, econômicos e sociais. Aqui se chega a um segundo limite do Novo Regionalismo contemporâneo, o foco de análise de grande parte dos trabalhos em período recente, posterior à década de 1980. No caso sul-americano, ao optar por essa aproximação temporal, estudos possibilitaram análises importantes dos eventos, com descrições detalhadas, em sua maioria voltadas às ações brasileiras e às características das instituições e processos de integração que se formaram nesse período (ex. GARDINI, 2010 e 2015; GARCÍA, 2010; RIGGIROZZI, 2012; MALAMUD, 2011; LAPP, 2012; SARAIVA, 2012; SOUZA, 2012; LIMA, 2013; RIGGIROZZI e TUSSIE, 2012; GOMÉZ-MERA, 2013; SORJ e FAUSTO, 2013; FLEMES e WEHNER, 2015; WEHNER, 2015; MERKE, 2015; RIGGIROZZI e GRUGEL, 2015; BRICEÑO-RUIZ e HOFFMANN, 2015; JENNE, SCHENONI e URDINEZ, 2017). No entanto, este recorte temporal e metodológico caracteriza uma perspectiva histórica limitada ao restringir as relaçóes regionais a eventos recentes. Tal opção pode ser uma das causas pela qual os estudos sobre a região estiveram focados, prioritariamente, nas interações e em análises de política externa. A falta de uma análise macro-histórica dificulta a compreensão sobre a possibilidade de mudanças sistêmicas mais estruturais, em virtude da maior estabilidade que as estruturas possuem diante das outras dimensóes. 
Quadro 1 - Modelo analítico do estudo de regióes de Castellano (2017)

\begin{tabular}{|c|c|c|}
\hline Nível de análise & $\begin{array}{l}\text { Elemento de } \\
\text { análise }\end{array}$ & Descriçáo \\
\hline \multirow[t]{4}{*}{ ESTRUTURA } & $\begin{array}{c}\text { Fundamento } \\
\text { estrutural }\end{array}$ & $\begin{array}{l}\text { Organização do sistema (princípio ordenador) e natureza } \\
\text { (tipo) predominante de unidades }\end{array}$ \\
\hline & Ordem & $\begin{array}{l}\text { Conjunto de valores, regras e normas políticas, } \\
\text { econômicas, socioidentitárias e securitárias do sistema, } \\
\text { que se estabelecem como instituiçóes formais ou informais }\end{array}$ \\
\hline & Polaridade & Distribuição de poder entre unidades \\
\hline & Fronteiras & Limites sistêmicos estabelecidos por meio das interaçóes \\
\hline \multirow[t]{2}{*}{ INTERAÇĀO } & Polarização & $\begin{array}{l}\text { Consolidação de alianças e rivalidades entre unidades em } \\
\text { blocos estáveis }\end{array}$ \\
\hline & $\begin{array}{c}\text { Padrão } \\
\text { Cooperaçáo- } \\
\text { Conflito } \\
\end{array}$ & Interação entre unidades (ações e reaçóes) \\
\hline \multirow[t]{2}{*}{ UNIDADES } & Política Externa & Posicionamento externo e comportamento das unidades \\
\hline & $\begin{array}{l}\text { Característica das } \\
\text { Unidades }\end{array}$ & Atributos e composição das unidades \\
\hline $\begin{array}{c}\text { FATOR } \\
\text { EXTERNO }\end{array}$ & $\begin{array}{c}\text { Penetraçáo } \\
\text { Extrarregional }\end{array}$ & Inserção de potências extrarregionais \\
\hline
\end{tabular}

Fonte: Adaptado de Castellano (2017, p. 58).

Assim, pode-se sintetizar em três pontos principais as lacunas da literatura do Novo Regionalismo sobre a América do Sul, sendo (1) a ausência de uma perspectiva que integre elementos e níveis de análise no estudo da região sul-americana; (2) a indefinição a respeito de elementos das unidades (os Estados) e da estrutura profunda do sistema regional; e (3) a limitada perspectiva histórica das análises, focadas prioritariamente em períodos e tendências recentes. Nossa proposta, portanto, busca romper com essas problemáticas a partir de um modelo analítico que analisa as relações regionais e suas tendências recentes de maneira integrada e ampla. Conforme o Quadro 1, essa perspectiva interpreta as regióes como sistemas próprios e autônomos, integrando quatro níveis de análise: o nível da estrutura, o nível da interaçáo, o nível das unidades e o nível externo. $\mathrm{O}$ emprego deste modelo, além de romper diretamente com o problema (1), da ausência de conexões entre níveis e elementos sistêmicos, permite avançar em relação ao problema (3), da limitação temporal das análises. Isso porque, ao interpretar as regióes como sistemas, torna-se 
possível uma análise que considera aspectos tanto de sua formação quanto das transformações sistêmicas, tornando possível uma abordagem macro-histórica.

Além dessa perspectiva, enfatizamos a importância adicional da incorporação explícita da perspectiva histórico-sociológica para romper o problema (2), da restrita vinculação analítica entre o Estado e os outros elementos sistêmicos regionais nos estudos sobre a região. Neste caso, em relação ao modelo adotado, destacam-se as contribuiçôes da Sociologia Histórica sobre processos de estruturação. Ou seja, a compreensão da natureza e dos efeitos de estruturas se conecta com processos históricos de mudança (SKOCPOL, 1985), contribuindo para avaliar conexóes causais entre o nível das unidades, a partir das dinâmicas dos Estados e das sociedades, em relação às dinâmicas regionais. No caso do problema que orienta este trabalho, a Sociologia Histórica contribui para que seja possível avaliar os processos de construção dos Estados e a conexão com as mudanças sistêmicas (HOBSON, 2003), já que "[...] os âmbitos doméstico e internacional são completamente interpenetrados e mutuamente constituídos [...]” (HOBSON, 2003, p. 16). Além disso, ampliamos essa noção para além do processo de formação dos Estados para abarcar as constantes transformações no âmbito das unidades e as dinâmicas das relações Estado-sociedade, num contínuo processo de co-constituição entre esses níveis de análise (AYOOB, 1999; HETTNE, INOTAI e SUNKEL, 2000; GRANT e SÖDERBAUM, 2003; CASTELLANO, 2017). Assim, a perspectiva da Sociologia Histórica parece ser coerente com o estudo das relaçôes internacionais e das regiôes, embora amplamente ignorada pela maioria dos estudos sobre a regiáo sul-americana.

Portanto, a proposta de análise do sistema regional sul-americano tem como objetivo entender as relações entre o Estado, enquanto elemento de agência sistêmica, e a estruturação do sistema regional como um todo, contemplando os aspectos definitivos desta abordagem no que diz respeito ao enfoque à natureza e efeitos de estruturas a partir de processos amplos (SKOCPOL, 1985; TILLY, 1985; ANSALDI e GIORDANO, 2012). Assim, a Sociologia Histórica, enquanto perspectiva teórica sobre processos macro-históricos, abre espaço para a compreensão contextual sobre a particularidade do processo de formaçáo dos Estados sul-americanos. Trata-se aqui de romper com outra dificuldade da disciplina de Relações Internacionais, qual seja, o domínio teórico e epistemológico ocidental que permeia as simplificaçôes e generalizações conceituais e analíticas (TICKNER, 2003; ACHARYA, 2011; SETH, 2011). Contribuições de autores e teóricos da própria região, assim como perspectivas 
de outras áreas de estudo, são fundamentais para pensar particularidades de processos ignorados pela literatura predominante das Relaçôes Internacionais. Importa que para compreender as questóes e dinâmicas mais detalhadas no nível das unidades, assim como seu potencial para impactar as estruturas do sistema regional, torna-se indispensável revisar estudos desenvolvidos na academia latino e sul-americana. Assim, ainda em relação ao problema (2), propomos também uma ênfase às características das unidades a partir de importantes contribuições históricas ao campo das Ciências Sociais, Ciência Política e Relaçôes Internacionais, por teóricos latino e sul-americanos que se dedicaram a analisar as características, os processos de formação e os desafios do Estado na regiáo.

\section{O Estado nas Relações Internacionais e nos estudos regionais: dimensões de análise e impactos sistêmicos}

O Estado nacional é uma categoria de análise que está profundamente ligada às Relaçóes Internacionais, já que as correntes teóricas predominantes na disciplina têm como foco prioritário de estudo as relações interestatais, debruçando-se sobre uma interpretação do Estado enquanto principal ator nas dinâmicas internacionais. $\mathrm{O}$ Estado é considerado por correntes teóricas do Realismo e Liberalismo, como o neorrealismo (WALTZ, 1979) e neoliberalismo institucional (KEOHANE, 1984), como o ator primário das relaçóes internacionais. Já outras abordagens teóricas, como o Construtivismo, a Escola Inglesa, e outras perspectivas pós-estruturalistas, agregam ao papel central do Estado as dinâmicas de atores não-estatais. No entanto, mantemse como característica predominante na disciplina a centralidade do Estado enquanto principal ator e unidade de análise. Entretanto, a perspectiva estruturalista dominante das teorias da Política Internacional carregou historicamente uma concepção ahistórica e imutável desta unidade de análise principal (RUGGIE, 1983 e 1989; HOBSON, 2003; HOLSTI, 2004).

Concomitantemente, no final do século XX, autores indiretamente ligados à disciplina expuseram em seus trabalhos essas problemáticas, afirmando que era necessário "trazer o Estado de volta" (EVANS, RUESCHEMEYER e SKOCPOL, 1985). A crítica foi generalizada aos estudos da Ciência Política que careciam de definiçôes mais precisas e análises mais profundas sobre as transformaçôes do Estado e seu impacto político, econômico e social dentro e fora de suas fronteiras (EVANS, RUESCHEMEYER e SKOCPOL, 1985; HALLIDAY, 1987; HOBSON, 2003). Uma das discussões mais importantes proposta por essa segunda geração da 
Sociologia Histórica (MAHONEY, 2000, 2004 e 2006) direcionou-se ao poder e capacidades dos Estados de agirem de forma articulada frente a grupos sociais. A literatura sobre capacidade estatal passou a definir e operacionalizar o conceito com diversos enfoques, ainda que seja comum, em trabalhos seminais como os Michael Mann (1984) ${ }^{3}$ e Joel Migdal (1988), uma noção que vincula o conceito à capacidade do Estado em superar os desafios de implementar suas políticas diante de constrangimentos territoriais e sociais (HANSON e SIGMAN, 2013). A disponibilidade de meios para que o Estado pudesse exercer sua capacidade teria implicaçóes significativas para seu grau de autonomia e para as relaçóes entre Estado e sociedade (MIGDAL, 1988). Na conceituação de Charles Tilly (1996 e 2007), essa aproximação também é sustentada, já que a capacidade estatal configura a capacidade do Estado em sustentar suas decisôes e orientações políticas a partir de seu relacionamento com a sociedade (TILLY, 2007). A capacidade estatal possui, assim, natureza relacional, em que ganha destaque, para além dos papeis das elites políticas, a agência da sociedade no Estado e na implementação de políticas públicas (REY, 2014). Por consequência, o papel de agência da sociedade torna-se fundamental para a consolidação de maiores níveis de capacidade estatal por parte dos Estados. Vinculada à construção de capacidades estatais está a discussão a respeito dos processos de state-building ou construção do Estado, no qual a construção de capacidades estatais tem origem e impacta na conformação de sistemas de Estados (TILLY, 1996 e 2007) ${ }^{4}$.

Alcançando o âmbito das Relações Internacionais, mais do que um debate a respeito do estado-centrismo da disciplina, essas discussões buscaram reforçar a necessidade de "[...] re-examinar o Estado e reafirmar sua centralidade em contextos históricos e contemporâneos" (HALLIDAY, 1987, p. 217, tradução nossa). Entretanto, tal avanço foi consolidado apenas parcialmente nas discussões teóricas da

\footnotetext{
${ }^{3} \mathrm{O}$ conceito de poder infraestrutural de Mann refere-se à “[...] capacidade institucional de um Estado [...] penetrar seus territórios e logisticamente implementar suas decisóes” (MANN, 1984, p. 113, tradução nossa).

${ }^{4} \mathrm{O}$ modelo de construção do Estado de Tilly baseia-se no caso europeu, no qual quatro atividades básicas caracterizariam o processo de construção dos Estados: as guerras, a consolidação do Estado, a proteção e a extração de recursos (TILLY, 1985). Em relação aos casos latino e sul-americanos, autores como Fernando López-Alves (2000), Miguel A. Centeno (2002) e Cameron Thies (2005) buscaram verificar a aplicação desse modelo na regiáo. Trataremos do processo sul-americano na seção seguinte deste trabalho.
} 
disciplina. No caso dos estudos sobre as regióes, análises como as de Björn Hettne, András Inotai e Osvaldo Sunkel (2000), e J. Andrew Grant e Fredrik Söderbaum (2003) têm abordado o papel do Estado e de seus processos de formação e estruturação como núcleo de dinâmicas regionais. O mesmo caminho foi seguido por Castellano (2017), que propóe um modelo que relaciona o impacto da construção do Estado à formação regional e configuração sistêmica 5 . Entretanto, essa perspectiva é ainda subdesenvolvida e se perde na infinidade de análises de perfil micro e mesohistórico, nas quais variações e transformações das unidades sistêmicas são recorrentemente ignoradas. O potencial da Sociologia Histórica nos estudos de sistemas internacionais e regional carece, portanto, de maior desenvolvimento - o qual pode ser incentivado por teorizações precedentes à própria restauração da perspectiva histórico-sociológica.

A literatura sobre Estado na América Latina e América do Sul antecipa as possibilidades que a Sociologia Histórica traz aos estudos regionais na medida em que reflete sobre a formação estatal e regional, por meio de dinâmicas políticas, econômicas e sociais. Autores latino-americanos como Celso Furtado (1968), Marcos Kaplan (1969), Fernando Henrique Cardoso e Enzo Faletto (1977), Guillermo O’Donnell (1978), Norbert Lechner (1981) e Oscar Oszlak (1981) já vinham desenvolvendo, antes dessa nova reorientação ao Estado proposta na disciplina, riquíssima produção sobre a categoria de Estado na América Latina. Como observam Granato e Batista (2017), estão presentes nas análises dos intérpretes latinoamericanos diversos aspectos do campo das Relaçóes Internacionais, caracterizando um "[...] ineditismo desses autores em relacionarem, em suas reflexôes, o âmbito interno estatal com conjunturas e estruturas internacionais" (GRANATO; BATISTA, 2017, p. 46), muito antes dessa tendência se fortalecer na disciplina de

\footnotetext{
${ }^{5}$ Esses processos poderiam manifestar-se de maneira direta e/ou indireta. No primeiro caso, mudanças nas unidades sistêmicas levam a um processo de estruturação, alterando diretamente o nível estrutural diante de mudanças na diferenciação funcional ou tipo das unidades sistêmicas. Mudanças no tipo das unidades são mudanças estruturais e, portanto, sistêmicas, capazes de alterar diretamente as estruturas profundas do sistema regional. De modo indireto, esse processo seria filtrado pela formulação de política externa, tal qual a proposta do realismo neoclássico. As principais formas nas quais se daria essa influência são relativas i) aos interesses que predominam na definição de política externa; e ii) à capacidade do Estado implementar suas políticas (CASTELLANO, 2017). Esses fatores “[...] explicariam o tipo de resposta dada pelas unidades frente aos constrangimentos sistêmicos que experimentam" (CASTELLANO, 2017, p. 93).
} 
Relações Internacionais. Com áreas de atuação distintas, estes autores parecem unidos, para além do objeto de estudo em comum, pela perspectiva teórica da Sociologia Histórica latino-americana (ANSALDI e GIORDANO, 2012). Resgatar essas contribuiçôes e refletir sobre elas, atualmente, parece ser uma forma de resgatar esses entendimentos e aprofundar as perspectivas teóricas dos estudos sobre as regiōes, informando um maior entendimento sobre o impacto das unidades na formação regional.

Os estudos sobre o Estado na América Latina estiveram voltados a análises que buscaram investigar estratégias e questões históricas comuns à região nos campos político, econômico e social. As características e especificidades do Estado foram estudadas a partir de uma contextualização histórica que considerava fenômenos políticos como os populismos, a questão desenvolvimentista e a dependência, as estratégias revolucionárias e os movimentos autoritários que marcaram a história da América Latina. Todas essas questóes, que parecem tão distintas e abarcaram períodos históricos diferentes, convergem no que diz respeito à centralidade do Estado nessas dinâmicas e das relaçóes sociais nele imbricadas (LECHNER, 1981). No campo político e nas relaçôes que nele se articulam, o Estado configura-se como um lócus de mediação e arbitragem dos conflitos sociais, constituindo-se como resultado de dinâmicas internas e fatores externos (KAPLAN, 1969).

Tal perspectiva contrasta com a literatura que reduz o Estado ao seu aparato, tratando-o como mero "ator" que cumpre determinado papel, caracterizando o que Lechner (1981) identifica como uma abordagem instrumental e funcionalista do Estado. O que a disciplina de Relaçôes Internacionais ignora, nesse sentido, não é o Estado em si, mas as dimensões sociais que vinculam Estado e sociedade (LECHNER, 1981), configurando o que podemos identificar como um caráter dual do Estado, tanto mecanismo de articulação das relações sociais quanto tradicional aparato institucional (OSZLAK, 1981). Por meio da ênfase nas relaçóes Estadosociedade, destaca-se a necessária percepção do Estado a partir de sua dimensão histórico-social, possibilitando uma mais profunda compreensão de seus dilemas de atuação e das mediações inerentes às suas relações (KAPLAN, 1969; O’DONNELL, 1978; LECHNER, 1981). O Estado, assim, deve ser visto a partir de um aspecto interacional em que as dimensóes internas e externas se co-constituem, e afetando e sendo afetado pelas relaçôes domésticas, regionais e internacionais. 
As relaçôes internacionais devem, portanto, ser concebidas, por um lado, como expressão e projeção das relaçóes sociais e da estrutura global do Estado em questão. Movimentos e mudanças nas estruturas internas afetam as relaçóes internacionais, através de expressóes e mecanismos econômicos, técnicos, políticos, militares e culturais. Por sua vez, por outro lado, as dinâmicas das relaçôes internacionais reagem às estruturas internas. As relaçôes internas de uma nação são combinadas com as relaçôes internacionais, complexas e heterogêneas em sua composição, na distribuição e imbricação de suas forças, e novas combinaçôes originais e específicas podem ser criadas. (KAPLAN, 1969, p. 68, tradução nossa).

Tendo em mente a complexidade de compreender as dimensóes externas e as características e relações que se estabelecem entre os Estados nesse âmbito, retomar percepções mais aprofundadas do Estado, assim como dar luz às relaçôes sociais que nele se articulam, possibilita que sejam construídas análises mais abrangentes sobre as relações regionais e internacionais nas quais esses Estados se articulam. Nesse sentido, Kaplan (1969) sintetiza como o Estado articula suas dimensões de atuação, relacionando o espaço internacional às dinâmicas internas e relaçóes sociais, e ressaltando como essas também são influenciadas por sua atuação no âmbito externo. Portanto, não se fala em Estado, mesmo que em seu âmbito externo, sem considerar igualmente suas relaçóes sociais.

Essas contribuições são complementadas, mais recentemente, por diversos estudos que buscaram aplicar ao caso latino-americano os debates sobre capacidade estatal. Barbara Geddes (1994), em um dos estudos pioneiros sobre a capacidade estatal na América Latina, buscou analisar como o comportamento dos indivíduos e das elites políticas responde a incentivos e cálculos de interesses em reformas e iniciativas políticas, dificultando a tradução das políticas implementadas em capacidade estatal nos Estados latino-americanos. Thies (2010) promove uma análise da relação entre a ocorrência de guerras civis e os níveis de capacidade estatal, concluindo que, enquanto os níveis de capacidade estatal não impactam a ocorrência de guerras civis, guerras civis reduzem a capacidade estatal. Soifer (2012) destacou a necessidade de incorporar o papel do Estado para entender e operacionalizar o conceito de capacidade estatal, e Grassi e Memoli (2016) investigaram o papel das características democráticas e da influência ideológica dos governos latino-americanos em seus níveis de capacidade estatal. Tais estudos auxiliam nas possibilidades de 
compreensão sobre impactos dos processos formativos dos Estados latino-americanos e do sistema regional.

É nesta perspectiva que buscaremos avaliar os impactos das transformaçôes dos Estados, suas capacidades e relações Estado-sociedade, com a formação do sistema regional. A proposta é ampliar o modelo de Castellano (2017) e observar os impactos dos processos formativos do Estado em outras variáveis estruturais, para além do tipo predominante das unidades sistêmicas e da política externa. Buscaremos desenvolver hipóteses sobre os mecanismos pelos quais Estados afetam toda a estrutura sistêmica regional, incluindo as fronteiras sistêmicas, a polaridade, a ordem e o princípio ordenador.

\section{O caso da América do Sul: impacto dos elementos das unidades na estrutura regional}

A importância do Estado para as relações e a configuração dos sistemas regionais vai além do aspecto de constituírem as unidades sistêmicas e estarem centralizados como agentes de suas interaçôes. Mais do que isso, seu impacto na formação e constituição desses sistemas é constante, tanto por meio de seus processos de construção, da sua formulação de política externa, quanto, a partir de uma noção ampliada de Estado, como mediador das relaçôes sociais, tanto no nível interno quanto externo. Tal relação e influência podem ser analisadas a partir de diferentes enfoques e problemas de pesquisa. Neste trabalho, observamos sua relação com aspectos da estrutura sistêmica regional, que abrange os elementos das fronteiras sistêmicas, da polaridade, da ordem e do princípio ordenador. Como síntese, propomos a hipótese, a ser testada de forma mais rigorosa em estudos futuros, de que existem três mecanismos principais pelos quais o Estado impacta os processos de estruturação regional, a saber: 1) como tipos/unidades constituintes do sistema, a partir dos processos de formação e transformação dos Estados; 2) como agentes das interações sistêmicas; e 3) como elementos estruturadores, a partir de suas características, relações e dinâmicas internas. A Figura 1 ilustra essa relação. 
Figura 1 - Mecanismos de impacto dos Estados nos processos de estruturação regional

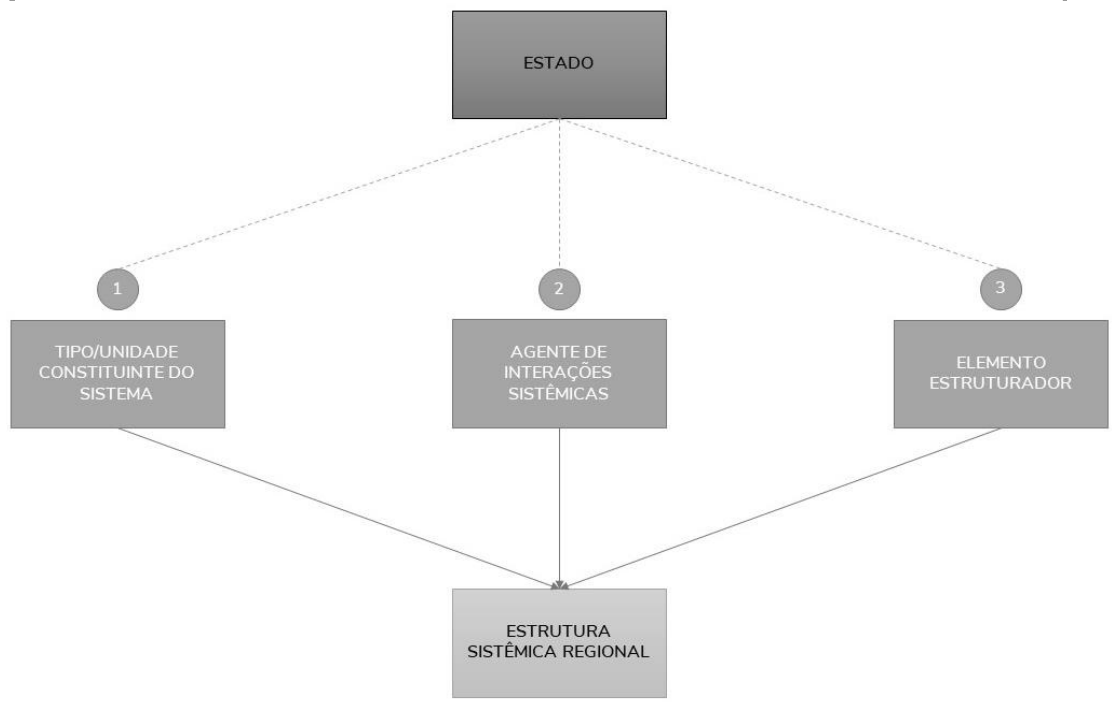

Fonte: Elaboração própria.

Temos como caso de análise o sistema regional sul-americano do pósindependência. Tal denominação já aponta para duas características estruturais que o fundam. Em primeiro lugar, refere-se à periodização atribuída, que marca a formação do sistema regional a partir da mudança no tipo predominante das unidades constituintes, paralelamente aos processos de independência e construção dos Estados nacionais, conforme proposto por Tilly (1996 e 2007) e operacionalizado por Castellano (2017). No período de 1810 a 1825 (CENTENO, 2002), na América do Sul, a independência dos Estados reduz a diferenciação das unidades em termos organizacionais, transformando gradualmente as colônias em Estados nacionais independentes. Com a mudança na diferenciação funcional das unidades, o sistema de Estados soberanos produziu um ordenamento do sistema caracterizado por um princípio ordenador anárquico, isto é, formado por unidades soberanas sem que haja a dominaçâo de uma sobre as demais (WALTZ, 1979). Assim, o processo de 
formação das unidades enquanto Estados nacionais ${ }^{6}$ é característico do primeiro mecanismo, definidor das unidades constituintes do sistema e da estruturação profunda, vinculados por um processo de coexistência.

O segundo aspecto estrutural é a delimitação da América do Sul como limite de suas fronteiras sistêmicas, devido ao grau de interaçôes políticas, econômicas, securitárias e socioidentitárias que se configuram entre suas unidades constituintes. Com isso não queremos dizer que a categoria de América Latina não é válida. Pelo contrário, tal classificação é capaz de dar conta de diversos outros aspectos que envolvem os Estados da regiáo. Mas, considerando os critérios teóricos adotados na definição dos sistemas regionais, a configuração das fronteiras sistêmicas dá-se a partir do grau de interação e dos vínculos construídos entre os países sul-americanos. Esse processo, no entanto, não é estático, sendo possível ao longo do tempo a expansão ou contração das fronteiras sistêmicas. Uma expansão desse sistema em direção a América Central e Caribe, a partir do estabelecimento de vínculos interacionais mais diretos com os países sul-americanos, poderia acarretar, por exemplo, uma mudança para um sistema regional latino-americano.

Os condicionantes para essas orientações residem, profundamente, nas características das unidades que os compõe. Vínculos diplomáticos e relações multilaterais entre os atores constituem-se a partir de seus posicionamentos de política externa, o que caracteriza um aspecto do papel de agência dos Estados nas interaçôes sistêmicas, conforme o segundo mecanismo proposto. Nesse sentido, há uma mudança incremental na qualidade desses vínculos a partir das mudanças constantes pelas quais passam as unidades sistêmicas. A própria definição de interação mais direta entre os Estados da região é relativamente recente, assim como a noção de que a América do Sul configura um sistema regional mais coerente do que a América Latina ${ }^{7}$.

\footnotetext{
${ }^{6}$ Cabe sinalizar que esses os resultados dos processos de construção do Estado diante das guerras de independência, conforme a teoria de Tilly para o caso europeu, não foram imediatos e, como destacam autores como Centeno (2002) e Thies (2005), não necessariamente positivos para o incremento das capacidades estatais. Delimitamo-nos aqui a enquadrar seu aspecto fundamente, já que o processo de estruturação passa, conforme o argumento deste trabalho, por processos vinculados ao mecanismo 3, a partir de características, relaçóes e processos internos aos Estados nacionais.

${ }^{7}$ Essa perspectiva foi incorporada, mais expressivamente, a partir dos anos 2000, tanto pela literatura quanto pelas mudanças na formulação de política externa dos Estados, que passaram a se referir mais a
} 
As mudanças e configuraçóes de outro aspecto da estrutura sistêmica, a polaridade, que corresponde à distribuição de capacidades materiais e imateriais entre as unidades, também podem ser interpretadas a partir de questôes próprias do nível das unidades, para além de outros condicionantes sistêmicos. No caso da América do Sul, é possível observar quatro grandes períodos de polaridade sistêmica com base na distribuição de capacidades materiais. Como estudos anteriores salientaram (VEDOVATO, 2017; CASTELLANO e VEDOVATO, 2019), as oscilações e mudanças nesse aspecto estáo geralmente relacionadas a guerras antecedentes (como as guerras de independência) e guerras centrais (como a Guerra do Paraguai e Guerra do Pacífico), definidoras de uma ordem de balanço de poder e da distribuição de poder tripolar entre Brasil, Argentina e Chile (VEDOVATO, 2017; CASTELLANO e VEDOVATO, 2019). As mudanças na distribuição de capacidades e na ordem regional a partir de guerras sistêmicas também estão relacionadas ao mecanismo 2, pois decorrem do papel do Estado enquanto agente das interaçóes sistêmicas a partir da política externa e sua atuação regional.

Contudo, há momentos significativos na análise macro-histórica em que observamos mudanças na polaridade sistêmica que não acompanham outras mudanças interacionais ou estruturais, sugerindo a possibilidade de influência direta de elementos internos no processo de estruturação sistêmica. Assim, aspectos como crises econômicas, regimes e transições políticas, governos eleitos e variações na capacidade estatal, típicos do terceiro mecanismo de influência do Estado nos sistemas regionais, parecem informar profundamente sobre processos internos incidindo sobre atributos de poder e capacidade dos Estados na região. Um exemplo no caso analisado são as mudanças que ocorrem na polaridade sistêmica após a consolidação da ordem de balanço de poder, caracterizada pela configuraçáo tripolar. A partir da década de 1920 é possível identificar o declínio chileno e, a partir da década de 1930, o início do declínio argentino, que viria a se consolidar na década de 1950, quando passaria a ser perceptível também um aumento nas capacidades brasileiras. Esses processos, que não se desencadeiam diretamente de mudanças interacionais ou estruturais, podem ser explicados pelos processos internos relativos aos Estados nesses períodos. O declínio do Chile, por exemplo, na década de 1920, é agravado no contexto da crise de 1929 e de reformas internas ao Estado. O declínio

América do Sul do que América Latina (CERVO, 2008; GALVÃO, 2009; SANTOS, 2014; VIGEVANI e CEPALUNI, 2013). 
da Argentina e a ascensão do Brasil parecem estar relacionados à sua desenvoltura no contexto da Segunda Guerra Mundial (1939-1945), mas também a processos relacionados a transiçóes políticas e crises políticas e econômicas típicos de suas dinâmicas internas.

Em relação à ordem regional, é neste elemento que o impacto estruturador de aspectos das unidades sistêmicas parece ser ainda mais direto. Isto porque a ordem sistêmica corresponde ao conjunto de "[...] valores, regras e normas políticas, econômicas, sócio-identitárias e securitárias do sistema, que se estabelecem como instituições formais ou informais e que constrangem açóes dos atores" (CASTELLANO, 2017, p. 62), e cuja operacionalização envolve uma percepção sobre o grau de institucionalização regional (VEDOVATO, 2017; CASTELLANO e VEDOVATO, 2019) ${ }^{8}$. A ordem é, portanto, um elemento da estrutura do sistema fundado em características majoritariamente imateriais, assemelhando-se em diversos aspectos ao que se entende por ordem também nos âmbitos estatais, podendo ser identificada como o grau de governo dos sistemas regionais. Assim como as estruturas estatais são responsáveis, no nível das unidades, por moldar a ordem interna e mediar suas açóes junto à sociedade que as constituí, de modo semelhante as potências regionais, articuladoras da ordem, moldam seu conteúdo a partir de seus objetivos e condicionantes internos, mediando sua atuação frente às potências secundárias e aos outros Estados articulados à ordem.

Apesar de se constituírem como elementos estruturais e, portanto, relativamente estáveis no sistema, as ordens sistêmicas podem variar em relação ao seu conteúdo (VEDOVATO, 2017; CASTELLANO e VEDOVATO, 2019). É nessa dimensão que se manifesta mais diretamente a relação do Estado como elemento estruturador, também característico do mecanismo 3. Em maior ou menor grau, características e dilemas internos ao Estado tendem a se reproduzir no conteúdo da ordem que articulam. Como Cardoso e Faletto (1977, p. 286, tradução nossa)

\footnotetext{
8 A partir das noçóes de institucionalização propostas por Huntington (2006), que associa a institucionalização ao processo pelo qual as instituiçôes, entendidas como padróes de comportamento recorrentes, adquirem valor e estabilidade (HUNTINGTON, 2006), sugere-se que a operacionalização do conceito de institucionalização seja feita a partir de três dimensôes principais: (i) a temporal-espacial, considerando instituiçóes formais e informais, (ii) a da aquiescência (aceitação ou consentimento em relação aos pressupostos da ordem), e (iii) a da autoridade (capacidade de governo em torno da ordem).
} 
sublinham, os Estados “[...] só podem atuar com força e credibilidade no plano externo quando a ordem política local é relativamente estável”. Pode-se contextualizar em dois sentidos essa questão. Primeiro, por um aspecto de prioridade de atuação do Estado. Estados com fortes demandas sociais e situações de conflito doméstico tendem a priorizar nas dinâmicas internas seu âmbito de atuação, afastando-se de questôes regionais ou internacionais. Dependendo de suas condiçóes e das características dos governos eleitos, também podem recorrer a essas dimensóes a fim de abrandar os conflitos internos ou, contrariamente, recorrer ao âmbito doméstico para abrandar conflitos regionais e interacionais. Segundo, os Estados tendem a repetir suas orientações internas no conteúdo da ordem que articulam.

Como exemplo, podemos citar dois momentos de ordem regional observados no caso da América do Sul${ }^{9}$. Da década de 1880 à década de 1980, é possível identificar uma ordem de balanço de poder articulada em torno de uma tripolaridade sistêmica entre Brasil, Argentina e Chile. O conteúdo dessa ordem refletia aceitação e satisfação das potências centrais com o status quo pós-guerras centrais e descontentamento das potências periféricas, sem, no entanto, haver uma contestação direta ao status quo estabelecido frente às potências regionais ${ }^{10}$. Apesar das mudanças na polaridade identificadas, conforme descrito anteriormente, a ordem permanece até meados dos anos 1980 refletindo o conteúdo do período anterior. Causas para esse panorama podem ser buscadas em questôes domésticas do Estado brasileiro, como constrangimentos internos e dilemas do Estado em se posicionar frente a um reordenamento sistêmico. A partir de 1980, com um novo aprofundamento da polaridade, novas configurações de alianças regionais e outras mudanças profundas na conjuntura interna vivenciada pelo Estado - como a transição democrática e as reconfigurações institucionais - possibilitam que o país se engaje mais efetivamente

\footnotetext{
${ }^{9}$ Uma análise específica dos diferentes períodos e características da ordem regional na América do Sul podem ser consultados em Vedovato (2017) e Castellano e Vedovato (2019).

${ }^{10}$ Nesse período, os Estados atuam de forma autônoma e pouco comprometidos com os valores e normas da ordem. Ademais, a existência de insatisfaçóes latentes, principalmente entre as potências secundárias, como Bolívia e Equador, caracterizam uma baixa aquiescência em torno da ordem. Em relação à autoridade, há um equilíbrio de açóes entre os Estados, que compartilham de noçóes como o não-enfretamento e o reconhecimento mútuo. Porém, sua autoridade era baixa, pois encontrava-se submetida aos Estados, que sustentavam seu aspecto de autonomia fundado na soberania estatal. Por conta disso, as mudanças são mais perceptíveis nos eixos estruturantes da ordem (VEDOVATO, 2017).
} 
no processo de construção da nova ordem regional que emerge após nova guerra central (Guerra das Malvinas) junto às potências secundárias e os outros atores regionais. Essa ordem vem a se consolidar mais fortemente a partir da década de 2000, configurando a tendência de uma ordem regional de governança, com alterações profundas em seu conteúdo. O conteúdo da ordem reflete, assim, o ambiente favorável interno que o país passou a vivenciar e características reformadas no Estado, que orientaram mudanças em sua política e posicionamento externo e buscaram imprimir no ordenamento regional seus objetivos em diversos setores, como, por exemplo, no aprofundamento da integração e institucionalização regional.

Para além das características e posicionamento das potências regionais articuladoras da ordem, cabe salientar o papel das potências secundárias e demais atores integrantes do ordenamento regional, visto que a dimensão da aquiescência depende em grande medida do segundo mecanismo, de agência das unidades sistêmicas, traduzida em satisfação ou insatisfação em relação à ordem sistêmica. Nesse sentido, o posicionamento das unidades frente a constrangimentos e oportunidades estruturais (ORGANSKI, 1968) também pode ter no nível das unidades e nas questóes estatais a fonte de maior entendimento para a construção de seu posicionamento e ímpeto de ação no sistema. Cabe salientar a vinculação que se estabelece, nesse sentido, entre as unidades sistêmicas, destacando-se os Estados que compóem o sistema regional e, no caso da ordem regional, a(s) potência(s) que a $\operatorname{articula}(\mathrm{m})$.

Quadro 2-Mecanismos de influência das unidades sobre a estrutura sistêmica regional

\begin{tabular}{|l|l|l|l|l|}
\hline \multicolumn{1}{|c|}{ Mecanismo } & Processo & $\begin{array}{l}\text { Elemento } \\
\text { estrutura } \\
\text { sistêmica }\end{array}$ & \multicolumn{1}{|c|}{ Efeito } & Ex. América do Sul \\
\hline $\begin{array}{l}\text { 1) Estado } \\
\text { como } \\
\text { tipo/unidade } \\
\text { constituinte do } \\
\text { sistema }\end{array}$ & Coexistência & $\begin{array}{l}\text { Fundamento } \\
\text { estrutural }\end{array}$ & $\begin{array}{l}\text { Definição do tipo } \\
\text { predominante das } \\
\text { unidades sistêmicas }\end{array}$ & $\begin{array}{l}\text { Processos de } \\
\text { independência e } \\
\text { consolidaçáo dos Estados } \\
\text { nacionais (período 1810- } \\
1825)\end{array}$ \\
\hline $\begin{array}{l}\text { 2) Estado } \\
\text { como agente } \\
\text { de interaçóes } \\
\text { sistêmicas }\end{array}$ & Agência & Ordem & $\begin{array}{l}\text { Orientação do conteúdo } \\
\text { na ordem regional a } \\
\text { partir da Política Externa } \\
\text { e atuação regional }\end{array}$ & $\begin{array}{l}\text { Configuração de uma } \\
\text { ordem regional de } \\
\text { governança centrada no } \\
\text { papel do Brasil a partir } \\
\text { de mudanças na política } \\
\text { e posicionamento }\end{array}$ \\
\hline
\end{tabular}




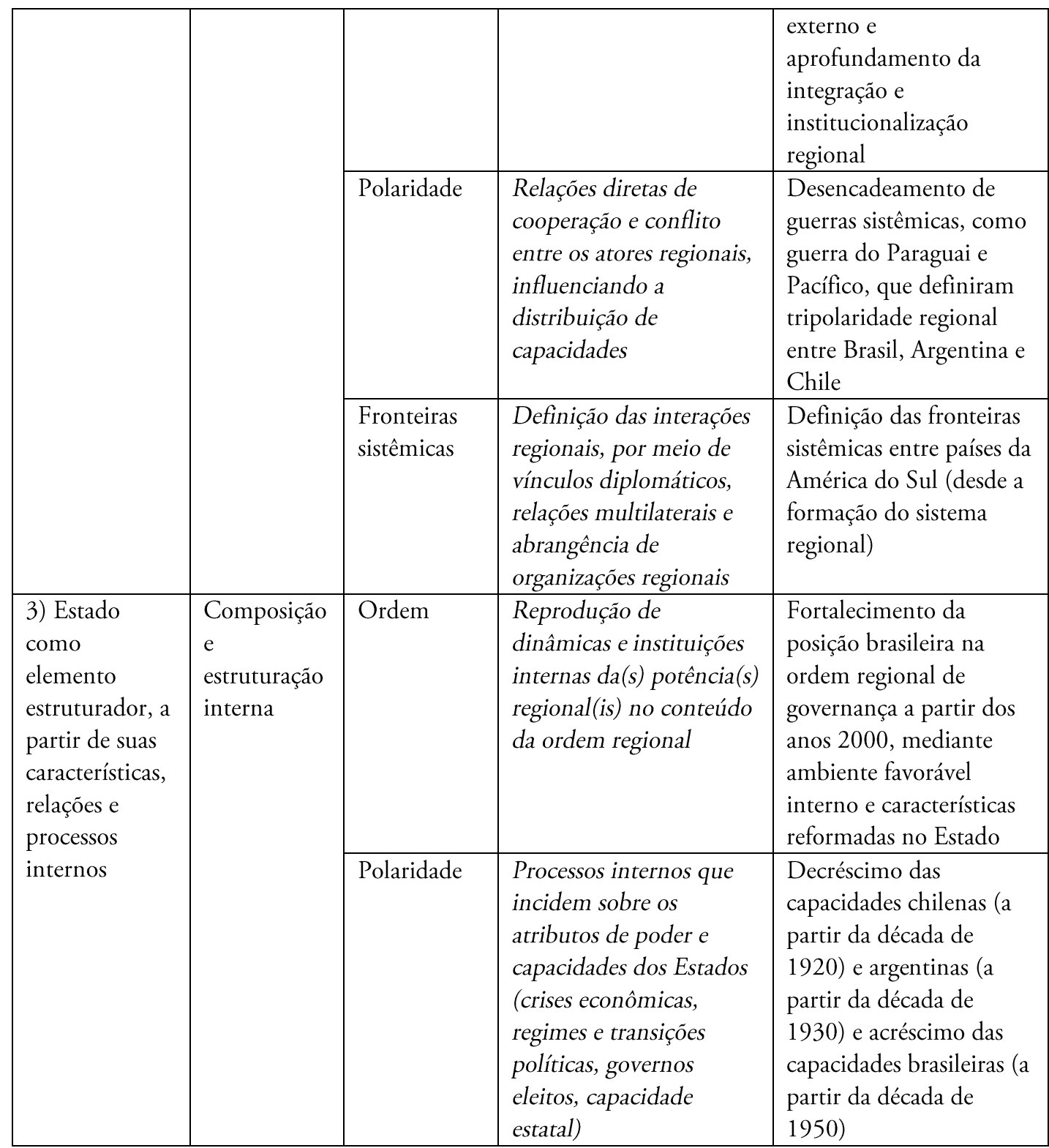

Fonte: Elaboração própria.

Enquanto as dinâmicas e transformações ocorrem de maneira constante no nível das unidades, os níveis interacional e, principalmente, o estrutural, são mais estáveis, passando por mudanças mais lentas. Porém, é importante observar que mudanças nos elementos interacionais e estruturais são filtradas e, como se sugere a 
partir da análise neste trabalho, condicionadas por questóes internas às unidades sistêmicas. Além disso, o nível das unidades informa constantemente dois mecanismos de estruturação do sistema: a polaridade, por meio da composiçáo de atributos de poder e capacidades do Estado, e a ordem regional, por meio da definição de seu conteúdo. A ordem regional, que reflete as características constituintes, objetivos e interesses dos Estados que nela se articulam, vincula-se diretamente aos eixos de preferência e instituiçóes sustentadas pelos seus governos e sociedades, refletindo no ordenamento regional características de suas instituições internas. O Quadro 2 sintetiza a análise da relação entre os mecanismos de influência das unidades sobre os elementos da estrutura sistêmica regional na América do Sul, identificando os processos pelos quais os mecanismos se relacionam a esses elementos, como se traduzem os efeitos e exemplos dessas relações no caso estudado.

\section{Considerações finais}

Este trabalho procurou contribuir para avanços na análise das relaçóes internacionais da América do Sul no campo do Novo Regionalismo por meio de estudo voltado à discussão teórica do impacto do nível das unidades na formação regional e em suas estruturas sistêmicas. Consideramos prioritariamente a influência da dimensão das características e aspectos formativos do Estado e das relações Estadosociedade. Ao incorporar aos estudos da regiâo sul-americana um foco na categoria do Estado, a partir de análise orientada pela Sociologia Histórica, buscamos conectar o Estado às questóes regionais e levantar questionamentos sobre a relação histórica entre mudanças estruturais e as características das unidades no sistema regional, auxiliando a identificação de padrôes, rupturas e tendências para a região.

Assim, entende-se que o Estado constitui categoria analítica a partir da qual podemos buscar explicação para a história e formação da região. Compreender as especificidades e características do Estado na região possibilita aprofundar as perspectivas teóricas oriundas do Novo Regionalismo, produzindo maior entendimento sobre o impacto das unidades na estrutura sistêmica regional. A adoção da perspectiva eclética e aliada à Sociologia Histórica possibilitou avaliar, ainda, a conexão dos processos históricos com as mudanças observadas no sistema regional sul-americano. Nesse sentido, as evoluções e mudanças pelas quais passam os sistemas regionais parecem estar condicionadas pelas características e processos históricos das unidades que o integram, sistematizadas neste trabalho em três principais mecanismos 
de impacto dos Estados nos processos de estruturação regional: 1) como tipos/unidades constituintes do sistema, a partir dos processos de formação e transformação dos Estados; 2) como agentes das interações sistêmicas; e 3) como elementos estruturadores, a partir de suas características, relações e dinâmicas internas.

Ademais, a temática revela-se determinante para que seja considerada a possibilidade de mudanças diretas em elementos da estrutura regional na composição e estruturaçáo de elementos como a polaridade e a ordem regional. $\mathrm{O}$ desafio de fortalecer as regiôes e construir ordens regionais mais estáveis e aceitas passa, assim, pelas dinâmicas internas aos Estados que nelas se articulam e dificuldades de fortalecimento de sua atuação, muitas vezes constrangidos por obstáculos mais robustos na consolidação de capacidades estatais. Adicionalmente, a porosidade dos sistemas regionais e a dependência em relação às potências extrarregionais, questôes históricas do Estado latino-americano, também parecem ser fatores determinantes para essa questão. Potências regionais em desenvolvimento dificilmente conseguem arcar com custos de políticas externas que garantam aquiescência regional sem o aprofundamento de suas capacidades estatais e estruturas institucionais e elementos contextuais internos favoráveis a esses processos. Por isso, manifesta-se a necessidade de adoção de políticas de Estado sustentáveis e de longo prazo para garantir a viabilidade desses projetos, passando pelo desafio de fortalecimento das relaçóes Estado-sociedade, o fortalecimento dos níveis de capacidade estatal e reconhecimento sobre o potencial estruturador do Estado para as dinâmicas regionais.

Ana Luiza Vedovato é Mestranda no Programa de PósGraduação em Estudos Estratégicos Internacionais da Universidade Federal do Rio Grande do Sul (PPGEEI-UFRGS) e bolsista CAPES. Pós-graduanda vinculada ao Grupo de Estudos em Capacidade Estatal, Segurança e Defesa (GECAP). E-mail: vedovatoanaluiza@gmail.com.

- Igor Castellano da Silva é Doutor em Estudos Estratégicos Internacionais pela Universidade Federal do Rio Grande do Sul. Professor Adjunto do Departamento de Economia e Relações Internacionais, do Programa de Pós-Graduação em Relações Internacionais e do Programa de Pós-Graduação em Economia e Desenvolvimento, da Universidade Federal de Santa Maria (UFSM). 


\section{Coordenador do Grupo de Estudos em Capacidade Estatal, Segurança e Defesa (GECAP) da UFSM. E-mail: igor.castellano@gmail.com.}

\section{Referências}

ABRAHAMSSON, Hans. Hegemon, Region and Nation-State: The case of Mozambique. In: HETTNE, Björn; INOTAI, András; SUNKEL, Osvaldo (Orgs.). National perspectives on the new regionalism in the South. Basingstoke: Palgrave Macmillan, 2000.

ACHARYA, Amitav. Dialogue and discovery: in search of International Relations theories beyond the West. Millennium: Journal of International Studies, v. 39, n. 3, p. 619-637, 2011.

ANSALDI, Giordano; GIORDANO, Verónica. América Latina, la construcción del orden: de la colonia a ta disolución de la dominación oligárquica. Buenos Aires: Ariel, 2012.

AYOOB, Mohammed. From regional system to regional society: exploring key variables in the construction of regional order. Australian Journal of International Affairs, v. 53, n. 3, p. 247-260, 1999.

- The Third World Security Predicament: State Making, Regional Conflict, and the International System. Boulder: Lynne Rienner, 1995.

BRICEÑO-RUIZ, José; HOFFMANN, Andrea Ribeiro. Post-hegemonic regionalism, UNASUR, and the reconfiguration of regional cooperation in South America. Canadian Journal of Latin American and Caribbean Studies, v. 40, n. 1, p. 48-62, Jan. 2, 2015. Disponível em: $<$ https://www.tandfonline.com/doi/full/10.1080/08263663.2015.1031475>. Acesso em: 17 maio 2019.

BURGES, Sean W. Revisiting consensual hegemony: Brazilian regional leadership in question. International Politics, v. 52, n. 2, p. 193-207, 2015.

. Consensual hegemony: theorizing Brazilian foreign policy after the Cold War. International Relations, v. 22, n. 1, p. 65-84, Mar. 2008. Disponível em: <http://journals.sagepub.com/doi/10.1177/0047117807087243>. Acesso em: 17 maio 2019.

CARDOSO, Fernando Henrique; FALETTO, Enzo. Post Scriptum a "Dependencia y Desarrollo em América Latina”. Desarrollo Económico, v. 17, n. 66, p. 273-299, 1977.

CASTELlanO, Igor. Política externa da África Austral: guerra, construção do Estado, e ordem regional (África do Sul, Angola, Moçambique, Zimbábue e Namíbia). Porto Alegre: CEBRÁFRICA-UFRGS, 2017.

CASTELLANO, Igor; VEDOVATO, Ana Luiza. New Regionalism and it's structural meanings: Brazil's leading role in the South American regional order. In: ISA's 60th Annual Convention, Toronto, 2019. 
CENTENO, Miguel Angel. Blood and Debt: War and the Nation-State in Latin America. University Park: The Pennsylvania State University Press, 2002.

CERVO, Amado Luiz. Inserção internacional: formação dos conceitos brasileiros. São Paulo: Saraiva, 2008.

CLAPHAM, Christopher. Third World politics: an introduction. London: Routledge, 1985.

EVANS, Peter B.; RUESCHEMEYER, Dietrich; SKOCPOL, Theda (Org.). Bringing the State back in. Cambridge: Cambridge University Press, 1985.

FAWCETT, Louise. Exploring Regional Domains: A Comparative History of Regionalism. International Affairs, v. 80, n. 3, p. 429-446, maio 2004. Disponível em: <https://academic.oup.com/ia/article-lookup/doi/10.1111/j.1468-2346.2004.00391.x>. Acesso em: 17 maio 2019.

FAWN, Rick. "Regions" and their study: wherefrom, what for and where to? Review of International Studies, v. 35, n. S1, p. 5, 2009. Disponível em: <http://www.journals.cambridge.org/abstract_S0260210509008419>. Acesso em: 17 maio 2019.

FLEMES, Daniel; WEHNER, Leslie. Drivers of strategic contestation: The case of South America. International Politics, v. 52, n. 2, p. 163-177, 2015.

FURTADO, Celso. Subdesenvolvimento e estagnação na América Latina. Rio de Janeiro: Civilização Brasileira, 1968.

GALVÃO, Thiago Gehre. América do Sul: construção pela reinvenção (2000-2008). Revista Brasileira de Política Internacional, v. 52, n. 2, p. 63-80, 2009.

GARCÍA, Carlos Alberto Chaves. La inserción internacional de Sudamérica: la apuesta por la Unasur. Íconos. Revista de Ciencias Sociales, n. 38, p. 29-40, 2010.

GARDINI, Gian Luca. Towards modular regionalism: the proliferation of Latin American cooperation. Revista Brasileira de Política Internacional, v. 58, n. 1, p. 210-229, June 2015. Disponível em: <http://www.scielo.br/scielo.php?script=sci_arttext\&pid=S003473292015000100210\&lng=en\&tlng=en>. Acesso em: 17 maio 2019.

. The origins of Mercosur: democracy and regionalization in South America. New York: Palgrave Macmillan $2010 . \quad$ US, Disponível em: <http://link.springer.com/10.1057/9780230105546>. Acesso em: 17 maio 2019.

GEDDES, Barbara. Politician's Dilemma: Building State Capacity in Latin America. Berkeley: University of California Press, 1994.

GÓMEZ-MERA, Laura. Power and regionalism in Latin America: the politics of MERCOSUR. Notre Dame: University of Notre Dame Press, 2013.

GRANATO, Leonardo; BATISTA, Ian Rebouças. Heterogeneidade Estrutural nas Relaçóes Internacionais da América Latina: um olhar através dos paradigmas de integração regional. Cadernos Prolam/USP, v. 16, n. 31, p. 5-29, jul./dez. 2017. DOI: 10.11606/issn.16766288.prolam.2017.133966.

GRANT, J. Andrew; SÖDERBAUM, Fredrik. The New Regionalism in Africa. Aldershot: Ashgate, 2003.

GRASSI, Davide; MEMOLI, Vincenzo. Democracy, political partisanship, and state capacity in Latin America. Rivista Italiana di Scienza Politica, v. 46, n. 1, p. 47-69, 2016. 
HALLIDAY, Fred. State and society in International Relations: a second agenda. Millennium Journal of International Studies, v. 16, n. 2, p. 215-229, 1987.

HANSON, Jonathan K.; SIGMAN, Rachel. Leviathan's latent dimensions: measuring State capacity for comparative political research. In: APSA 2011 Annual Meeting, set. 2013. Disponível em: <http://ssrn.com/abstract=1899933>. Acesso em: 17 maio 2019.

HEMMER, Christopher; KATZENSTEIN, Peter. Why is there no NATO in Asia: collective identity, regionalism, and the origins of multilateralism. International Organization, n. 56, p. 575-607, 2002.

HETTNE, Björn; INOTAI, András; SUNKEL, Osvaldo. National perspectives on the New Regionalism in the South. London: Macmillan Press, 2000.

HOBSON, John M. The State and International Relations. Cambridge: Cambridge University Press, 2003.

HOLSTI, Kalevi J. The state, war, and the state of war. Cambridge: Cambridge University Press, 2004.

HUNTINGTON, Samuel P. Political Order in Changing Societies. New Haven and London: Yale University Press, 2006

HURRELL, Andrew. Explaining the resurgence of regionalism in world politics. Review of International Studies, v. 21, n. 4, p. 331-358, 26 out. 1995. Disponível em: <http://www.journals.cambridge.org/abstract_S0260210500117954>. Acesso em: 17 maio 2019.

JENNE, Nicole; SCHENONI, Luis Leandro; URDINEZ, Francisco. Of words and deeds: Latin American declaratory regionalism, 1994-2014. Cambridge Review of International Affairs, v. 30, n. 2-3, p. 195-215, Mar. 4, 2017. Disponível em: <https://www.tandfonline.com/doi/full/10.1080/09557571.2017.1383358>. Acesso em: 4 maio 2019.

KAPLAN, Marcos. Estado y Sociedad (Notas para un esquema analítico). In: KAPLAN, Marcos. El Estado em el desarrollo y la integración de América Latina: Ensayos. Caracas: Monte Ávila, 1969. p. 14-74.

KELLY, Robert E. Security Theory in the "New Regionalism". International Studies Review, v. 9, n. 2, p. 197-229, 2007.

KEOHANE, Robert O. After Hegemony: Cooperation and Discord on the World Political Economy. Princeton: Princeton University Press, 1984.

LAPP, Nancy D. Resistance is útil (useful): responses to Brazilian hegemony. In: WILLIAMS, Kristen P.; LOBELL, Steven E.; JESSE, Neal G. (Org.). Beyond great powers and hegemons: why secondary states support, follow or challenge. Stanford: Stanford University Press, 2012. p. 145160.

LECHNER, Norbert (Ed.). Estado y política en América Latina. México D.F.: Siglo Veintiuno Editores, 1981.

LIMA, Maria Regina Soares de. Relações interamericanas: a nova agenda sul-americana e o Brasil. Lua Nova: Revista de Cultura e Política, v. 90, p. 167-201, 2013.

LIMA, Maria Regina Soares de; HIRST, Monica. Brazil as an intermediate state and regional power: action, choice and responsibilities. International Affairs, v. 82, n. 1, p. 21-40, 2006. 
LÓPEZ-ALVES, Fernando. State formation and democracy in Latin America, 1810-1900. Durham: Duke University Press, 2000.

MAHONEY, James. On the second wave of Historical Sociology, 1970s-present. International Journal of Comparative Sociology, v. 47, n. 5, p. 371-377, Oct. 26, 2006. Disponível em: <http://journals.sagepub.com/doi/10.1177/0020715206068619>. Acesso em: 17 maio 2019.

. Revisiting General Theory in Historical Sociology. Social Forces, v. 83, n. 2, p. 459-489,

Dec. 1, 2004. Disponível em: <https://academic.oup.com/sf/articlelookup/doi/10.1353/sof.2005.0018>. Acesso em: 17 mai. 2019.

Path dependence in historical sociology. Theory and Society, v. 29, n. 4, p. 507-548, 2000.

MALAMUD, Andrés. A leader without followers? The growing divergence between the regional and global performance of Brazilian foreign policy. Latin American Politics \& Society, v. 53, n. 3, p. 1 24, 2011.

MALAMUD, Andrés; RODRIGUEZ, Júlio C. Com um pé na regiáo e outro no mundo: o dualismo crescente da política externa brasileira. Estudos Internacionais, v. 1, n. 2, p. 167-183, 2013.

MANN, Michael. The autonomous power of the State: its origins, mechanisms and results. European Journal of Sociology, v. 25, n. 2, p. 185-213, 1984.

MERKE, Federico. Neither balance nor bandwagon: South American international society meets Brazil's rising power. International Politics, v. 52, n. 2, p. 178-192, 2015.

MIGDAL, Joel S. Strong societies and weak States: State-Society relations and State capabilities in the Third World. Princeton, New Jersey: Princeton University Press, 1988.

O’DONNELL, Guillermo. Apuntes para una teoría del Estado. Revista Mexicana de Sociología, v. 40, n. 4, p. 1157-1199, 1978.

ORGANSKI, Abramo F. K. World politics. New York: Knopf, 1968.

OSZLAK, Oscar. The historical formation of the State in Latin America: some theoretical and methodological guidelines for its study. Latin American Research Review, v. 16, n. 2, p. 3-32, 1981.

REY, Maximiliano. Capacidad estatal y poder del Estado en Latinoamérica del siglo XXI: una perspectiva política para el análisis de las políticas públicas y la estatalidad. Revista Estado y Políticas Públicas, v. 2, n. 2, p. 115-139, 2014.

REZENDE, Lucas Pereira. Brasil: ator unipolar na América do Sul? Carta Internacional, v. 11, n. 1, p. 274, 30 abr. 2016. Disponível em: <https://www.cartainternacional.abri.org.br/Carta/article/view/355>. Acesso em: 17 maio 2019.

RIGGIROZZI, Pía. Region, regionness and regionalism in Latin America: towards a new synthesis. New Political Economy, v. 17, n. 4, p. 421-443, Sep. 2012. Disponível em: <http://www.tandfonline.com/doi/abs/10.1080/13563467.2011.603827>. Acesso em: 17 maio 2019.

RIGGIROZZI, Pía; GRUGEL, Jean. Regional governance and legitimacy in South America: the meaning of UNASUR. International Affairs, v. 91, n. 4, p. 781-797, July 2015. Disponível em: <https://academic.oup.com/ia/article-lookup/doi/10.1111/1468-2346.12340>. Acesso em: 17 maio 2019. 
RIGGIROZZI, Pía; TUSSIE, Diana. The Rise of Post-Hegemonic Regionalism. Dordrecht: Springer Netherlands, 2012. Disponível em: <http://link.springer.com/10.1007/978-94-007-2694-9>. Acesso em: 17 maio 2019.

RODRIGUEZ, Júlio César Cossio. Chacal ou Cordeiro? O Brasil frente aos desafios e oportunidades do Sistema Internacional. Revista Brasileira de Política Internacional, v. 55, n. 2, p. 70-89, Dec. 2012. Disponível em: <http://www.scielo.br/scielo.php?script=sci_arttext\&pid=S0034$73292012000200005 \& \operatorname{lng}=$ pt\&tlng=pt $>$. Acesso em: 17 maio 2019.

RUGGIE, John Gerard. International Structure and International Transformation: Space, Time and Method. In: ROSENAU, James N.; CZEMPIEL, Ernst-Otto. (Orgs.). Global Changes and Theoretical Challanges: Approaches to World Politics for the 1990s. Lexington: Lexington Books, 1989. p. 21-36.

. Continuity and Transformation in the World Polity: Toward a Neorealist Synthesis. World Politics, v. 35, n. 2, p. 261-285, Jan. 13, 1983. Disponível em: <http://www.journals.cambridge.org/abstract_S0043887100005268>. Acesso em: 17 maio 2019.

SANTOS, Luís Cláudio Villafañe G. A América do Sul no discurso diplomático brasileiro. Brasília: FUNAG, 2014. Disponível em: <http://funag.gov.br/loja/download/1099-aamerica-do-sul-nodiscurso-dimplomatico-brasileiro.pdf>. Acesso em: 17 maio 2019.

SARAIVA, Miriam Gomes. Procesos de integración de América del Sur y el papel de Brasil: los casos del Mercosur y la Unasur. Revista CIDOB d'Afers Internacionals, n. 97-98, p. 87-100, 2012.

SCHENONI, Luis Leandro. Regional Power Transition: Lessons from the Southern Cone. Hamburg: GIGA Working Papers, 2016.

. Brasil em América del Sur La lógica de la unipolaridad regional. Nueva Sociedad, v. 250, p. 138-149, 2014.

As possíveis causas domésticas da liderança brasileira na América do Sul. Contexto Internacional, v. 34, n. 2, p. 659-691, dez. 2012a. Disponível em: $<$ http://www.scielo.br/scielo.php?script=sci_arttext\&pid=S0102-

85292012000200009\&lng=pt\&tlng=pt>. Acesso em: 17 mai. 2019.

- Ascenso y hegemonía: pensando a las potencias emergentes desde América del Sur. Revista

Brasileira de Política Internacional, v. 55, n. 1, p. 31-48, 2012b. Disponível em: <http://www.scielo.br/scielo.php?script=sci_arttext\&pid=S0034-

73292012000100003\&lng=es\&tlng=es $>$. Acesso em: 17 maio 2019.

SETH, Sanjay. Postcolonial Theory and the critique of International Relations. Millennium - Journal of International Studies, v. 40, p. 167-183, 2011.

SKOCPOL, Theda. Bringing the State back in: strategies of analysis in current research. In: EVANS, Peter B.; RUESCHEMEYER, Dietrich; SKOCPOL, Theda (Orgs.). Bringing the State back in. Cambridge: Cambridge University Press, 1985. p. 3-43.

SOIFER, Hillel David. Measuring State capacity in contemporary Latin America. Revista de Ciência Política, v. 32, n. 3, p. 585-598, 2012.

SORJ, Bernardo; FAUSTO, Sergio. O Brasil e a Governança da América Latina: Que Tipo de Liderança é Possível? São Paulo: Fundação Instituto Fernando Henrique Cardoso (IFHC), 2013. 
SOUZA, Nilson Araújo de. América Latina: as ondas da integração. OIKOS, v. 11, n. 1, p. 87-126, 2012.

SPEKTOR, Matias. Ideias de ativismo regional: a transformação das leituras brasileiras da região. Revista Brasileira de Política Internacional, v. 53, n. 1, p. 25-44, 2010.

TEIXEIRA, Carlos Gustavo Poggio. Brazil and the institutionalization of South America: from hemispheric estrangement to cooperative hegemony. Revista Brasileira de Política Internacional, v. 54, n. 2, p. 189-211, 2011.

THIES, Cameron G. Of rulers, rebels, and revenue: State capacity, civil war onset, and primary commodities. Journal of Peace Research, v. 47, n. 3, p. 321-332, 2010.

War, rivalry, and State building in Latin America. American Journal of Political Science, v. 49, n. 3, p. 451-465, 2005.

TICKNER, Arlene. Seeing IR differently: notes from the Third World. Millennium: Journal of International Studies, v. 32, p. 295-324, 2003.

TILLY, Charles. Democracy. New York: Cambridge University Press, 2007.

- Coerção, capital e Estados europeus. São Paulo: Editora da Universidade de São Paulo, 1996.

War Making and State Making as Organized Crime. In: EVANS, Peter B.; RUESCHEMEYER, Dietrich; SKOCPOL, Theda (Orgs.). Bringing the State back in. Cambridge: Cambridge University Press, 1985. p. 169-191.

VALE, Peter. Security and Politics in South Africa: The Regional Dimension. London: Lynne Rienner, 2003.

Dissenting Tale: Southern Africa's search for theory. In: VALE, Peter; SWATUK, Larry. A.; ODÉN, Bertil. (Orgs.). Theory, change and Southern Africa's future. New York: Palgrave Macmillan, 2001. p. 17-33.

The Botha Doctrine: Apartheid, Southern Africa and the West. In: CHAN, Stephen (Ed.). Exporting Apartheid: Foreign Policies in Southern Africa, 1978-1988. London: Macmillan, 1990. p. $170-178$.

VARAS, Augusto. Brazil in South America: from indifference to hegemony. [S.l.]: FRIDE Working Papers, 2008. Disponível em: <http://fride.org/publication/415/brazil-in-south-america:-fromindifference-to-hegemony>. Acesso em: 17 maio 2019.

VEDOVATO, Ana Luiza. Ordem regional na América do Sul: mudanças e causas sistêmicas (18102010). 2017. 71 f. Trabalho de Conclusão de Curso (Bacharelado em Relações Internacionais) Centro de Ciências Sociais e Humanas, Universidade Federal de Santa Maria, 2017.

VIGEVANI, Tullo; CEPALUNI, Gabriel. A Política Externa Brasileira: a busca da autonomia, de Sarney a Lula. 2. ed. São Paulo: Editora UNESP, 2013.

VIGEVANI, Tullo; RAMANZINI JÚNIOR, Haroldo. Pensamento brasileiro e integração regional.

Contexto Internacional, v. 32, n. 2, p. 437-487, dez. 2010. Disponível em: $<$ http://www.scielo.br/scielo.php?script=sci_arttext\&pid=S0102-

$85292010000200006 \& \operatorname{lng}=$ pt\&tlng=pt $>$. Acesso em: 17 maio 2019.

WALTZ, Kenneth W. Theory of International Politics. Reading: Addison-Wesley, 1979.

WEHNER, Leslie E. Role expectations as foreign policy: South American secondary powers' expectations of Brazil as a regional power. Foreign Policy Analysis, v. 11, n. 4, p. 435-455, Oct. 
2015. Disponível em: <https://academic.oup.com/fpa/article-lookup/doi/10.1111/fpa.12048>. Acesso em: 17 maio 2019.

WENDT, Alexander. The agent-structure problem in international relations theory. International Organization, v. 41, n. 3, p. 335-370, 1987. Disponível em: <http://journals.cambridge.org/abstract_S002081830002751X>. Acesso em: 6 ago. 2014.

Texto recebido em 07 de dezembro de 2018. Aprovado em $1^{\circ}$ de maio de 2019. 